Recepción: 13 / 08 / 2018

Aceptación: $28 / 11 / 2018$

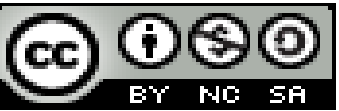

Ciencias de la salud

Publicación: 20 / 01 / 2018

\title{
El Sida y su connotación en la práctica odontológica
}

\author{
AIDS and its connotation in dental practice
}

\author{
AIDS e sua conotação na prática odontológica
}

\author{
Jessenia A. Gálvez-Ortega ${ }^{\mathrm{I}}$ \\ jesseniagalvezortega@gmail.com \\ Verónica R. Huacon-Cherrez ${ }^{\text {II }}$ \\ dra.veronicahuaconch.ug@gmail.com
}

Correspondencia: jesseniagalvezortega@gmail.com

\footnotetext{
I Especialista en Estética y Operatoria Dental, Odontóloga, Docente de la Universidad de Guayaquil, Guayaquil, Ecuador.

II Diploma Superior en Implantología, Especializacao Em Periodontia, Especializacao Em Implantodontia, Odontóloga, Docente de la Universidad de Guayaquil, Guayaquil, Ecuador.
} 


\section{Resumen}

En los últimos años se ha tomado gran importancia el crecimiento de la infección con el VIH en la población. Lograr una actualización acerca del efecto de SIDA en la especialidad de odontología es la finalidad de nuestro trabajo. Sobre la base de tales reflexiones se realiza una exhaustiva revisión bibliográfica donde se exponen algunos aspectos relacionados con las vías de transmisión de esta enfermedad, la bioseguridad, tratamiento y las manifestaciones bucales presentes.

Palabras claves: VIH/SIDA; odontología; promoción; prevención.

\section{Abstract}

In recent years, the growth of HIV infection in the population has become very important. Achieving an update about the effect of AIDS in the specialty of dentistry is the purpose of our work. Based on these reflections, an exhaustive literature review is carried out, where some aspects related to the transmission routes of this disease, biosecurity, treatment and oral manifestations are exposed.

Keywords: HIV / AIDS; odontology; promotion; prevention.

\section{Resumo}

Nos últimos anos, o crescimento da infecção pelo HIV na população tornou-se muito importante. Conseguir uma atualização sobre o efeito da AIDS na especialidade da odontologia é o objetivo do nosso trabalho. Com base nessas reflexões, realiza-se uma revisão exaustiva da literatura, onde são expostos alguns aspectos relacionados às vias de transmissão dessa doença, biossegurança, tratamento e manifestações bucais.

Palavras-chave: HIV / AIDS; odontologia; promoção; prevenção.

\section{Introducción}

Desde la más remota antigüedad existen enfermedades relacionadas con la sexualidad; sin embargo toca en la actualidad vivenciar las causas del incremento y de esta forma se concluye que el decrecer de la edad de la madurez sexual con una entrada más temprana a la vida sexual 
activa, la libertad sexual cada vez mayor, la existencia de tratamiento eficaz para algunas ITS que ofrecen una falsa seguridad en las poblaciones jóvenes quienes desconocen la farmacorresistencia, y olvidan la posibilidad de adquirir una infección-enfermedad VIH/SIDA, la comercialización del sexo, la industria del sexo, turismo sexual con su exponente máximo: el trabajador sexual, han favorecido el aumento de las cifras a nivel internacional.(Mendoza Fonseca, N., Serrano Borrego, Y., Forment Poutou, Z., Fernández Justiz, R 2015)

Las infecciones de transmisión sexual (ITS) son un problema de salud pública, por lo que es necesario conocer su comportamiento para poder realizar acciones de promoción y prevención que permitan su control y por ende lleven a que estas se disminuyan. (Informe de Evento VIH/SIDA, Colombia, 2017).

Dentro de estas infecciones de transmisión sexual se encuentra el Virus de la Inmunodeficiencia Humana (VIH), donde su forma tardía es el síndrome de Inmunodeficiencia Adquirida SIDA, el cual también puede transmitirse de la madre al hijo durante el embarazo, el parto y la lactancia e igualmente por transfusiones sanguíneas, o en usuarios de drogas intravenosas. (Informe de Evento VIH/SIDA, Colombia, 2017).

El SIDA es la forma más grave y la etapa final de la infección por VIH, esta enfermedad provoca una grave deficiencia en los mecanismos de defensa del organismo, el VIH ataca a los linfocitos T4 que son una clase de glóbulos blancos que rigen el sistema inmunitario, penetra en esas células donde se replica y a la larga las destruye. La destrucción de estos glóbulos blancos causa una deficiencia en las respuestas inmunitarias de la persona. (Organización Mundial de la Salud. SIDA y familias. Washington: Asociación Estadounidense para la salud; 1994)

El VIH es un virus neurotrópico implica que además de atacar al sistema inmunológico, afecta al sistema nervioso central, incluso desde los primeros estadios de la enfermedad, como han apuntado varios autores. Por tanto, es común que los pacientes infectados, al margen de las posibles alteraciones neurocognitivas que puedan presentar de forma secundaria a la inmunodepresión, presentan síntomas de naturaleza propiamente neurológica y neuropsicológica (Bragança y Palha, 2011). 
Se acota que el SIDA se ha convertido en un problema de salud mundial sin precedentes en la historia contemporánea. Además de serias preocupaciones de salud, está acarreando importantes repercusiones sociales, políticas y económicas en los países desarrollados y en vías de desarrollo. Desde 1981, cuando se conoció por primera vez la existencia de este síndrome, la epidemia ha avanzado hasta llegar a afectar a casi todas las comunidades del mundo. (Marchán Margolles M, Seijo Machado M 2000). En este contexto, se exige una respuesta apremiante y la necesidad de contar con recursos económicos, políticos, sociales y psicológicos que hagan frente a una problemática con tal magnitud.

Al reflexionar sobre su diseminación, es preciso considerar las transformaciones de esta patología en su contexto histórico, principalmente en relación a las formas de transmisión, a las tendencias de vulnerabilidad de la enfermedad y también, a los significados construidos para enfrentar esa realidad. (Tosoli Gomes A, Pinto Silva E, Oliveira E 2011).

La calidad y la esperanza de vida de las personas que viven con VIH/sida (PVVS) podrían equipararse a la del resto de la población. A pesar de esto, la percepción social hacia quienes viven con VIH continúa negativa. Sus vías de transmisión, sus implicaciones respecto a los mandatos de género más tradicionales y su asociación con el imaginario social a grupos socialmente excluidos causan estigma y discriminación en distintos ámbitos. (May MT, Gompels M, Delpech V, Porter K, Orkin C, Kegg S, et al 2014), (Layer EH, Kennedy CE, Beckham SW, Mbwambo JK, Likindikoki S, Davis WW 2014). (Elizondo J E, Treviño A, Violant D 2015)

\section{Interrelación del VIH en la Odontología}

La OMS promulga: Hoy en día debe aceptarse que las infecciones por VIH y SIDA es considerad una pandemia. El odontólogo forma parte del equipo de profesionales de la salud, y como tal, está expuesto a tratar con pacientes infectados por VIH y enfermos del SIDA que no lo saben o quienes por temor a ser rechazados en consulta no manifiestan su condición. (OMS: La salud bucodental: repercusión del VIH/SIDA en la práctica odontológica. Washington, DC: OMS, 1995.) 


\section{Manejo de la Salud Oral del Paciente SIDA/VIH}

La atención de las personas VIH positivos, no es de mayor complejidad ni distinta al requerido por las personas VIH negativas, debido a que el protocolo de control de infecciones rige para toda persona que recibe atención clínica. En el caso de las personas VIH positivas, el tratamiento oportuno que se brinde sirve para mantener y restituir la función dental y especialmente para prevenir infecciones intraorales, relacionadas con mayor énfasis en las que guardan relación con la sobrecarga del sistema inmunológico, dentro de las cuales destacan las afecciones periodontales. (Organización Mundial de la Salud. SIDA y familias. Washington: Asociación Estadounidense para la salud; 1994): Agendamos hacer énfasis en el personal de salud y particularmente en el personal que conforma los equipos humanos de atención bucodental, que los tratamientos preventivos y clínicos, guardan profunda relación con aspectos como el mejoramiento de la autoestima, así como también produce beneficios y efectos psicológicos positivos en las personas seropositivos y con SIDA. (Organización Mundial de la Salud. SIDA y familias. Washington: Asociación Estadounidense para la salud; 1994)

\section{Manejo del paciente con VIH / SIDA}

Los pacientes infectados por VIH están médicamente comprometidos y su estado de salud puede cambiar rápidamente, haciendo especialmente importante que los profesionales dentales obtengan un historial actualizado y completo de salud. La cuidadosa evaluación de la salud del paciente puede ayudar a determinar las influencias potenciales de la etapa de la enfermedad de VIH, en la planificación dental del tratamiento. Para ayudar a determinar la etapa de la enfermedad de VIH, se debe obtener del paciente toda información posible. Los pacientes están generalmente informados en cuanto a su condición y estado. (Principios para el Manejo de la Salud Oral del Paciente SIDA/VIH. 2000)

Es de necesidad priorizada un intervalo de conocimiento para dedicarnos al tratamiento bucodental de la persona infestada por el VIH:

El tratamiento debe ser cometido con juicios claros de adaptación a las condiciones generales del paciente; relacionamos: 
Es esencial las acciones de promoción y prevención con la existencia de cobertura de protección obligatoria (aplicación de soluciones tópicas fluoradas, sellantes de fosas y fisuras)

Con relación a los abordajes invasivos, el tratamiento periodontal es fundamental seguido de los tratamientos restaurativos.

No están contraindicados los tratamientos endodoncicos, protésicos y ortodontico.

Los procedimientos de exodoncia u otro tipo quirúrgico deben ser realizados normalmente, el manejo de los efectos inflamatorios pos quirúrgicos deben tenerse en cuenta por estar relacionado con un mayor riesgo de infección.

No existen contraindicaciones en el uso de soluciones anestésicas locales. (Protocolo de atención de personas con VIH. 2009)

\section{Lesiones orales presentes en pacientes con VIH.}

Las lesiones y manifestaciones en la cavidad oral pueden generar cambios en la apariencia facial, dificultad para hablar, disfagia, xerostomía, mala higiene oral, dolor y molestias que pueden alterar seriamente el estado de salud y calidad de vida de los pacientes. (Lifson AR 1993)

Es sumamente importante la identificación de las lesiones orales en pacientes con SIDA, ya que el tratamiento adecuado de las mismas se basa en el correcto diagnóstico y considerando el factor de inmunosupresión bajo el cual se encuentran, merecen y requieren un manejo especial. (González M, Pérez de Monferrato, P, Velázquez Llamas. A 2011); el odontólogo puede desempeñar un papel esencial en el tratamiento odontológico general y en la disminución del riesgo de transmisión en la consulta; diferentes autores hacen referencia que la presencia de lesiones orales sugiere que un individuo puede estar infectado por el VIH y otras lesiones pueden ayudar a indicar el pronóstico para la progresión del SIDA, además son un indicador de la progresión de la enfermedad: Nos acercaremos a los eventos orales relacionadas con el SIDA los cuales pueden clasificarse en:

Micóticas. 


\section{Virales.}

\section{Bacterianas.}

Neoplásicas. (Marchena Rodríguez, L, Fernández Ortega, C M, García García, B. 2015)

Entre las micóticas podemos señalar la candidiasis como la más común en pacientes infectados por VIH; entre las virales se han encontrado la leucoplasia vellosa; otra manifestación viral es la del herpes simple. (Marchena Rodríguez, L, Fernández Ortega, C M, García García, B. 2015)

Candidiasis: La candidiasis se presenta en más de un 50\% de los pacientes infectados, siendo la eritematosa la que predomina en los primeros estadios y la seudomembranosa en los pacientes que han desarrollado la enfermedad SIDA. Los pacientes por espejo tienen lesiones simultáneas en paladar y dorso de lengua. (Manejo del paciente con Sida en la consulta odontológica. 2014).

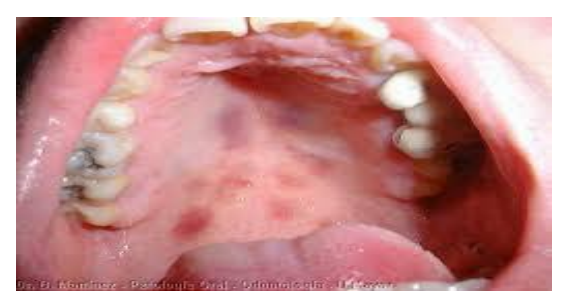

Leucoplasia vellosa: Se presenta como una lesión blanquecina, de superficie corrugada, no removible, en los bordes laterales de la lengua en un 10\% de los pacientes infectados con el virus del SIDA. Su diagnóstico debe confirmarse con una biopsia. (Manejo del paciente con Sida en la consulta odontológica. 2014.

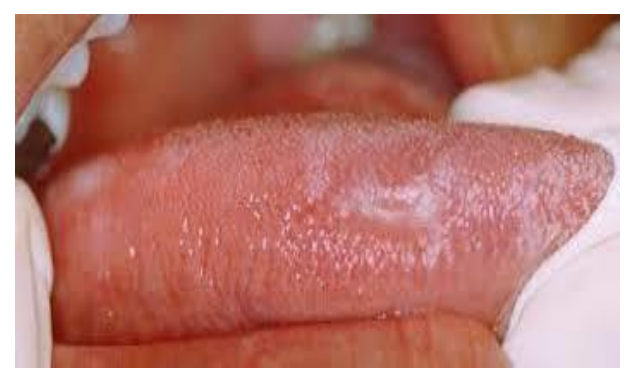


Herpes simple. Se hace referencia a todas las lesiones labiales e intrabucales causadas tanto por VHS-1 y VHS-2. El virus se transmite por contacto directo, siendo la puerta de entrada más común la faringe seguida de la vía genital, y el período de incubación va de unos pocos días a dos semanas, luego del cual se puede producir la enfermedad primaria o gingivoestomatitis herpética primaria.( (Cardozo Montilla M, Tovar V, Guerra M . 2009)

En cuanto a las manifestaciones bacterianas se presentan directamente sobre los tejidos periodontales, se han encontrado lesiones gingivales con características muy similares a la gingivitis úlcero-necrotizante aguda con una rápida progresión, que causa destrucción ósea asociada con una supresión severa del sistema inmune.( .(Marchena Rodríguez, L, Fernández Ortega, C M, García García, B. 2015).

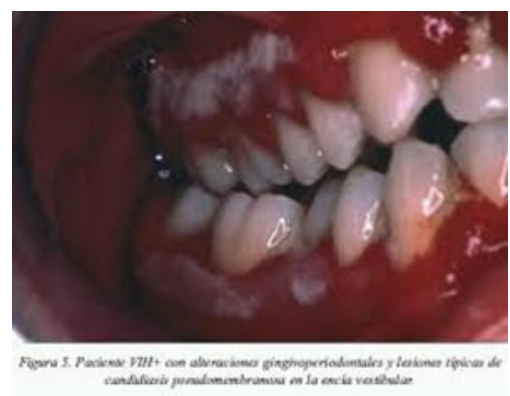

Entre el grupo de la neoplasia, la más relacionada con el VIH es el sarcoma de Kaposi, se inicia como una mancha o placa eritematosa o violácea que no hace relieve. Su localización habitual es el paladar o la encía, pero lo hemos visto en la lengua. La lesión progresivamente va haciendo relieve hasta convertirse en una masa tumoral de crecimiento rápido. Simultáneamente se pueden apreciar otras lesiones en diferentes partes del cuerpo. Es necesaria la confirmación con una biopsia. (Marchena Rodríguez, L, Fernández Ortega, C M, García García, B. 2015), (Barr Ch. 1992)

Literaturas revisadas refieren la no existencia de un consenso sobre la magnitud de la prevalencia de estas lesiones orales, posiblemente porque se ven afectadas por características sociodemográficas y clínicas; propias de cada individuo y por las particularidades de cada población. (Greenwood I, Zakrzewska J, RobinsonP 2002) 


\section{Bioseguridad en la práctica odontológica}

El riesgo de transmisión de ciertas enfermedades durante procedimientos relacionados con el tratamiento odontológico, ha cobrado mucho interés en los últimos tiempos. Es imposible conocer a ciencia cierta si un paciente es portador de un proceso infeccioso, por lo tanto, todo paciente debe considerarse como posible transmisor de infecciones, por lo que debe atenderse bajo las máximas condiciones clínicas que prevengan la contaminación del profesional estomatológico o de otros pacientes. (VIH/SIDA, En la atención de la salud bucal. 2006)

Gran número de infecciones pueden transmitirse durante procedimientos relacionados con el tratamiento odontológico, esto no quiere decir que el proceso de tratamiento dental sea el causante de la infección, sino que, al no tenerse en cuenta el área y el ambiente clínico donde se realizan estos procedimientos, existe la posibilidad de contaminación con microorganismos patógenos que pueden causar infección. La fuente de contaminación con microorganismos puede ser el paciente o cualquiera de los miembros del equipo profesional odontológico. Las posibles vías de transmisión son:

De paciente a profesional.

Del profesional al paciente.

Entre pacientes.

\section{Las infecciones con importancia en odontología pueden clasificarse en 3 grandes grupos:}

Infecciones de las vías respiratorias.

Enfermedades de la niñez.

Enfermedades transmitidas sexualmente. (VIH/SIDA, En la atención de la salud bucal. 2006)

Es innegable que la Bioseguridad es un instrumento de comportamientos que logra tener actitudes y conductas que minimizan el riesgo del trabajador de la salud en este caso odontólogo, higienista dental y colaboradores de adquirir o transmitir infección en el ámbito donde desempeña su función. y no permitir la transmisión cruzada; al efectuar los procederes odontológicos de práctica, pueden causar pequeños sangrados o incluso observar sangrados espontáneos, además la cavidad bucal es portadora de una multiplicidad de agentes microbianos 
por lo que inferimos que el odontólogo puede contaminarse o contaminar accidentalmente.( VIH/SIDA . En la atención de la salud bucal. 2006).

Es recomendable el conocimiento de las medidas cautelares de protección, nos referiremos:

Materiales infecciosos:

- $\quad$ Tejidos fluidos y corporales

- $\quad$ Material y equipo médico utilizado en pacientes infectados

- $\quad$ Superficie y ambiente infectado

Rutas de contaminación.

- $\quad$ Contacto directo: piel, mucosa

- $\quad$ Contacto indirecto; mucosa - superficie contaminada

- $\quad$ Contacto de aerosoles y fluidos en suspensión.

- Transmisión área.

- Transmisión por equipos médicos. (Protocolo de atención de personas con VIH. 2009).

Marchán Margolles (2000) en su artículo científico hace alusión a medidas específicas a tener en cuenta en odontología; relacionamos:

\section{Uso de elementos aisladores:}

Los guantes deben usarse cuando exista la posibilidad de establecer contacto con la sangre o saliva contaminada con sangre, y el estomatólogo, previo al tratamiento de cada paciente, debe lavarse las manos antes de colocarse los guantes y después del tratamiento.

\section{Manejo de instrumentos punzo-cortantes:}

Existen instrumentos punzo-cortantes como las agujas, bisturíes, alambres y tijeras, que pueden ser usados en el paciente de acuerdo con el tratamiento indicado, por lo que estos instrumentos deben considerarse como infecciosos, y por lo tanto, deben manipularse con cuidado para evitar 
accidentes y pinchazos. Se recomienda mantener las agujas dentro de su tapa durante el tratamiento y también la realización de la guardia durante el uso del instrumental de tartrectomía.

\section{Esterilización del instrumental:}

La esterilización del instrumental es otro aspecto que se debe considerar dentro de las medidas de control del SIDA, es decir, que todo aquel instrumento que se utilice debe ser esterilizado, ya sea usando vapor bajo presión (autoclave) o calor seco (horno), de acuerdo con las normas de esterilización, y el equipo para dicha esterilización debe ser mantenido y regulado periódicamente. (Marchán Margolles, Seijo Machado, M 2000)

Gallardo-Rosales R (2016) notifico en su estudio que las lesiones orales en PVVIH están asociadas mayormente a un conteo de linfocitos TCD4 bajo, independientemente de la terapia antirretroviral que reciben y la carga viral que presenten al momento del examen bucal. Así mismo investigación realizada por Harris Ricardo J y colaboradores (2013) relacionada con las lesiones orales asociabas a tratamiento antirretroviral y carga viral, resulto que los pacientes tratados con monoterapia farmacológica antirretroviral presentaron menos lesiones bucales que aquellos tratados con biterapia.

Autores Bravo I, Correnti M, Escalona E y colaboradores (2006) en su investigación identificaron que la lesión oral más frecuente fue la Candidiasis bucal, seguida por la Leucoplasia vellosa, Leucoplasia bucal, e Hiperpigmentación melánica. Una alta carga viral estuvo fuertemente asociada a la presencia de lesiones, independientemente del contaje de células CD4+.

Para dar por concluido, un sistema inmune deteriorado predispone a los pacientes a la aparición y desarrollo de lesiones orales muchas veces de etiología oportunista y se presume que con un control odontológico periódico en los pacientes se realizaría la detección temprana de cualquier manifestación oral. 


\section{Referencias Bibliográficas}

M Barr Ch. Manifestaciones orales en la infección por VIH. Rev Ateneo Argent Odontal 1992;29 (2): 43-53.

Bravo IM, Correnti M, Escalona L, Perrone M, Brito A, Tovar V, Rivera H. (2006). Prevalencia de lesiones bucales en pacientes $\mathrm{VIH}+$, relación con contaje de células CD4+ y carga viral en una población Venezolana. Recuperado de http://www.medicinaoral.com/medoralfree01/v11i1/medoralv11i1p33e.pdf

Bragança, M.; Palha, A. (2011)."Trastornos neurocognitivos asociados con la infección por el VIH". Actas Esp Psiquiatr; 33, 374-83.

Cardozo Montilla M, Tovar V, Guerra M. (2009). Prevalencia de Herpes bucal en pacientes VIH positivos atendidos en el Centro de Atención a Personas con Enfermedades Infectocontagiosas durante el período 1999-2004.Recuperado de https://www.actaodontologica.com/ediciones/2009/1/art-3/

Elizondo J E, Treviño A, Violant D. La odontología y el estigma asociado al VIH. Rev Saúde Pública 2015; 49: 79.

González M, Pérez de Monferrato, P, Velázquez Llamas. A. Lesiones orales presentes en pacientes con VIH. Rev. Inst. Med. Trop.2011; 6 (1)

Greenwood I, Zakrzewska J, RobinsonP. Changes in the prevalence of HIV-associated mucosal disease at a dedicated clinic over 7 years. Oral Dis 2002; 8: 90-4.

Gallardo-Rosales R, Castillo-Torres K, Alegría-Conejeros P, Blackburn-Tapia E. (2016). Manifestaciones orales en pacientes con VIH / SIDA. Recuperado de http://www.scielo.org.co/pdf/ceso/v29n2/v29n2a03.pdf

Harris Ricardo J, Díaz Caballero A, Fortich Mesa N. (2013). Revista Cubana de Investigaciones Biomédicas.; 32(3): 284-292

INFORME DE EVENTO VIH7SIDA, COLOMBIA, (2017). Recuperado de https://www.ins.gov.co/buscador-eventos/Informesdeevento/VIH-SIDA\%202017.pdf 
Layer EH, Kennedy CE, Beckham SW, Mbwambo JK, Likindikoki S, Davis WW, et al. (2014) Multi-levelfactors affecting entry into and engagement in the HIV continuum of care in Iringa, Tanzania. PLoS One.; 9 (8):e104961. DOI:10.1371/journal.pone.0104961

Lifson AR. (1993). Oral lesions and epidemiology of HIV. En Greenspan JS, Greenspan D. Editores. Oral manifestations of HIV infection: Proceedings of 2nd International workshop on the oral manifestations of HIV infection. Jan 31st- Feb 3rd

Marchán Margolles, M, \& Seijo Machado. (2000). El SIDA: Su repercusión en Estomatología. Revista Cubana de Estomatología, 37(3), 171-175. Recuperado en 15 de diciembre de 2018, de http://scielo.sld.cu/scielo.php?script=sci_arttext\&pid=S0034$75072000000300007 \& \operatorname{lng}=\mathrm{es} \& \operatorname{lng}=\mathrm{es}$.

Manejo del paciente con Sida en la consulta odontológica. (2014). Recuperado de https://www.odontologos.mx/odontologos/noticias/982/manejo-del-paciente-con-sida-en-laconsulta-odontologica

Mendoza Fonseca, N., Serrano Borrego, Y., Forment Poutou, Z., \& Fernández Justiz, R. (2015). Algunas consideraciones teóricas sobre ITS/VIH/sida. Revista Información Científica, 90(2), 362-373. Recuperado de http://www.revinfcientifica.sld.cu/index.php/ric/article/view/255/1102

May MT, Gompels M, Delpech V, Porter K, Orkin C, Kegg S, et al. Impact on life expectancy of HIV-1 positive individuals of CD4+ cell count and viral load response to antiretroviral therapy. AIDS. 2014; 28 (8):1193-202. DOI:10.1097/QAD.0000000000000243

Principios para el Manejo de la Salud Oral del Paciente SIDA/VIH. (2000.) Recuperado de https://aidsetc.org/sites/default/files/resources_files/princ-sp.pdf

Protocolo de atención de personas con VIH. (2009) Recuperado. http://www.paho.org/hq/dmdocuments/2009/OH_COR_AtencVIHPractOdontSegSoc.pdf

OMS. (1995) La salud bucodental: repercusión del VIH/SIDA en la práctica odontológica. Washington, DC: OMS, 1995.

Organización Mundial de la Salud. (1994). SIDA y familias. Washington: Asociación Estadounidense para la salud. 
Tosoli Gomes A, Pinto Silva E, Oliveira E. Representaciones sociales del SIDA para personas que viven con HIV y sus interfaces cotidianas. (2011). Rev. Latino-Am. Enfermagem; 19 (3)

VIH/SIDA. En la atención de la salud bucal. (2006).Recuperado de http://www.msp.gub.uy/sites/default/files/archivos_adjuntos/INTERIOR\%20Salud\%20Bucal\%2 0pacientes $\% 20$ con $\% 20$ enfer $\% 20$ sistemicas $\% 20 \% 281 \% 29$.pdf 